\title{
Socio-economic status and enrollment in higher education: Do costs matter?
}

\author{
Koen Declercq Frank Verboven*
}

September 3, 2014

\begin{abstract}
We study the impact of socio-economic status on enrollment and study decisions in higher education. We use a discrete choice approach to distinguish between three channels. First, students from disadvantaged backgrounds may be more sensitive to the costs of education. Second, they may have lower preferences for education. Third, they may have developed less academic ability during previous schooling and are therefore less likely to participate. We apply our analysis to Flanders, where tuition fees are low and all high school graduates have access to higher education. We control for unobserved heterogeneity and find that preference and (acquired) ability are more important than cost sensitivity in explaining the lower enrollment of disadvantaged students. Finally, we use the cost sensitivity channel to simulate the impact of tuition fee increases. We find that a uniform tuition fee increase has a fairly small impact on total enrollment, but it especially reduces enrollment of socially disadvantaged students. An alternative discriminatory policy, which combines a tuition fee increase with an extra subsidy to disadvantaged students, can be superior: it reduces the participation gap of disadvantaged students without decreasing total enrollment in higher education.
\end{abstract}

JEL Classification: I21, I22, I23, I28

Keywords: Discrete choice analysis, higher education, socio-economic status

*Koen Declercq: University of Leuven and Ph.D. fellow of the Research Foundation Flanders (FWO), email: Koen.Declercq@kuleuven.be. Frank Verboven: University of Leuven and CEPR, email: Frank.Verboven@kuleuven.be. We would like to thank Otto Toivanen, Jo Van Biesebroeck and participants of the Fifth International Workshop of Applied Economics of Education in Catanzaro. We would also like to thank the Flemish Ministry of Education for providing the datasets. 


\section{Introduction}

Governments aim to ensure a high participation of students in higher education. However, there is a large gap in enrollment between students from disadvantaged backgrounds and students from advantaged backgrounds. For many OECD countries, Asplund et al. (2004) show that enrollment rates differ substantially according to the educational degree of the parents. Bailey and Dynarski (2011) show for the U.S. that overall participation in higher education has increased over time, but that this increase was smaller for low-income families. As college graduates on average earn higher wages, children from low-income families can improve their socio-economic status by investing in higher education. To increase the participation of these students, governments implement financial aid programs ${ }^{1}$ and provide scholarships for low-income students.

We study the impact of socio-economic status on enrollment and study decisions in higher education. We use a discrete choice model to distinguish between three channels through which socio-economic status influences enrollment and study decisions. First, students from disadvantaged backgrounds may participate less in higher education because they are more sensitive to the costs of education. Second, they may be less likely to enroll because of lower preferences for education. This preference effect captures the fact that disadvantaged students have lower tastes for education, higher indirect costs of studying or lower expectations about the returns of the investment. Third, students from disadvantaged backgrounds have lower (acquired) academic ability when they graduate from high school. Academic ability is an important determinant of study decisions and is also influenced by socio-economic background, as shown by Dahl and Lochner (2012) and Lundborg et al. (2014).

We apply our analysis to Flanders, the Dutch-speaking part of Belgium, where tuition fees are low and institutions are not allowed to set their own admission standards. All high school graduates can choose almost any program in higher education. This unique setting allows us to observe the most preferred option of each student since choices are hardly constrained. Students can choose between academic and professional programs. Academic programs are offered at universities and colleges, while professional programs are only offered at colleges.

We use a unique dataset about all high school graduates of 2008, eligible to enter higher education in Flanders. We combine this dataset with a dataset of all students in higher education. We observe gender, age, high school background and socio-economic status. We measure the socio-economic status of the student by the following variables: educational degree of the mother, study grant in secondary education and language spoken at home.

\footnotetext{
${ }^{1}$ Deming and Dynarski (2009) review experimental and quasi-experimental research evidence on the causal relationship between college costs and educational attainment. They find that well-designed financial aid programs increase the participation in higher education.
} 
The study grant variable is our proxy for household income because low-income families obtain a subsidy for children in secondary education. We also observe detailed information on the students' locations, from which it is possible to compute travel costs to all study options (the sum of transport costs and the opportunity cost of travel time to attend a professional or academic program).

We proceed with our analysis in several steps. We first estimate the discrete choice model to uncover the determinants of study choice, in particular socio-economic background. We then use the parameter estimates to quantify the relative importance of the above three channels through which socio-economic background may influence enrollment in higher education. Finally, we perform policy counterfactuals to investigate the effects of raising tuition fees. We distinguish between uniform tuition fees for all students, and discriminatory fees to advantaged students, accompanied with subsidies to disadvantaged students. We discuss the results from these steps in turn.

First, the empirical results from our discrete choice model reveal the following. Students from disadvantaged backgrounds are less likely to enroll in higher education. If they participate, they are more likely to choose for one-cycle, professional programs at college. Students with less favorable socio-economic characteristics are also more sensitive to the costs of education. There is also significant unobserved heterogeneity, both regarding student sensitivity to travel costs and regarding the preferences of studying (relative to not enrolling). These factors are often neglected in previous studies, but turn out to be relevant for our further analysis.

We next use the parameter estimates to quantify the impact of the three channels through which socio-economic background influences enrollment in higher education. We do this by predicting study decisions of disadvantaged students as if this group would have similar characteristics as the advantaged students. We find that the preference and especially the (acquired) ability effects are more important in explaining the lower participation of disadvantaged students than the cost sensitivity effect. According to the most general mixed logit model (which captures heterogeneity in both travel cost sensitivity and preferences for studying), relaxing the three effects together would increase total enrollment in higher education by 8.4 percentage points (from $69.9 \%$ to $78.3 \%$ ). Relaxing the (acquired) ability and preference effects would increase participation by respectively 6.5 and 1.8 percentage points, while relaxing the cost sensitivity effect leads to an increase in participation of only 0.4 percentage points. Note that the decomposition gives similar results in the nested logit (which accounts for unobserved heterogeneity in preferences for studying, but not in travel cost sensitivity). In contrast, the conditional logit model (which does not account for unobserved heterogeneity) predicts a much larger cost sensitivity effect. This demonstrates the 
importance of accounting for unobserved heterogeneity to obtain unbiased results. Because in our most general mixed logit model the cost sensitivity effect only explains a small part of the participation gap, we conclude that policies to improve academic ability will be more effective than financial incentives to increase the participation of disadvantaged students.

Finally, we use the model to evaluate the effect of tuition cost increases on enrollment. Tuition costs currently only cover approximately $3 \%$ of the total costs of higher education in Flanders (Cantillon et al., 2006), and there is increasing pressure to raise tuition fees. It is thus highly relevant to assess the impact of tuition fee increases on enrollment. We find that a 1000 euro tuition fee increase that is uniform to all students would reduce participation by 3.0 percentage points for disadvantaged students, and by only 1.9 percentage points for advantaged students. We therefore consider alternative discriminatory tuition fee policies, which raise tuition fees by 1000 euro for advantaged students, combined with a budget-neutral subsidy increase for disadvantaged students. Such a policy would leave total enrollment more or less unchanged, and reduce the gap between both socio-economic groups: enrollment of disadvantaged students would increase $(+3.0$ percentage points) at the expense of a reduction in enrollment of advantaged students (-1.9 percentage points).

Our work relates to various strands in the literature on the effects of socio-economic status and financial aid on enrollment in higher education. A first strand of the literature focusses on the impact of socio-economic status on enrollment. Family income, parental education and race are important determinants of the participation decision, see for example Steiner and Wrohlich (2012), Acemoglu and Pischke (2001), Frenette (2006) and Cameron and Heckman $(2001)^{2}$. Most studies find that effect of socio-economic status on enrollment in higher education decreases when controlling for academic ability developed during previous schooling, see for example Baert and Cockx (2013) and Galindo-Rueda et al. (2004) ${ }^{3}$. Consistent with our findings, Carneiro and Heckman (2002) conclude that the long run effects associated with socio-economic status, such as cognitive and noncognitive ability, are more important than credit constraints in explaining the participation gap. Stinebrickner and Stinebrickner (2003) suggest that family background is more important than the direct costs of education in explaining the difference in college outcomes by family income.

\footnotetext{
${ }^{2}$ Steiner and Wrohlich (2012) find significant effects of family income and the educational degree of the mother on the probability of choosing for university. Acemoglu and Pischke (2001) find that a 10 percent increase in family income is associated with a 1.4 percent increase in the probability of attending a four-year college. Frenette (2006) demonstrates that students from lower-income families are particularly disadvantaged by distance in their enrollment decision. Cameron and Heckman (2001) find that minorities are less likely than whites to attend college.

${ }^{3}$ Baert and Cockx (2013) demonstrate that the ethnic gap in participation in tertiary education is eliminated when controlling for family background and previous schooling. Galindo- Rueda et al. (2004) conclude that much of the impact from social class on university attendance actually occurs well before entry into higher education.
} 
A second strand of the literature focusses on the impact of financial incentives on enrollment. Financial aid programs increase the number of students in higher education. Cornwell et al. (2006) demonstrate that Georgia's HOPE program, a merit based scholarship, increased freshmen enrollment by 5.9\%. Abraham and Clark (2006) and Dynarski (2002 and 2003) finds that a $\$ 1000$ increase in study grants increases participation by approximately 4 percentage points. Kelchtermans and Verboven (2010), Nielsen et al. (2010) and Steiner and Wrolich (2012) find much smaller effects of study grants on participation. They conclude that a 1000 euro increase in subsidies increases participation by about 1 to 1.5 percentage points. While tuition fee subsidies have a small effect on the participation decision, Kelchtermans and Verboven (2010) and Goodman (2008) find that they have a stronger effect on where and what to study.

Our contribution is to combine both literatures and systematically evaluate the relative importance of the above three channels through which socio-economic status can influence enrollment in higher education. Based on these findings we can then focus on the cost sensitivity channel to simulate the effect of additional tuition fees and subsidies to disadvantaged students.

The remainder of this paper is organized as follows: Section 2 provides an institutional overview of the higher education system in Flanders, and takes a first look at the rich register data, describing first-year enrollment and socio-economic background. Section 3 sets up the empirical model and describes the assumptions of the three discrete choice models. Finally, section 4 discusses the empirical results and quantifies the impact of socio-economic status on study decisions. Section 5 describes the impact of tuition fees on enrollment in higher education.

\section{Higher education in Flanders}

We start with a description of higher education in Flanders. We only discuss institutional aspects that are relevant for the rest of the paper ${ }^{4}$. We introduce our dataset and provide some descriptive statistics of study decisions of high school graduates. These statistics already illustrate the importance of socio-economic status on study decisions in higher education.

\footnotetext{
${ }^{4}$ Dassen and Luijten-Lub (2007) and De Ro (2008) provide more detailed information about education in Flanders.
} 


\subsection{Institutional overview}

Flanders ${ }^{5}$ is the Dutch-speaking part of Belgium, located in the North. It consists of about $60 \%$ of the population of 11 million inhabitants, compared with $40 \%$ in the French-speaking part, which is located in the South and most of Brussels ${ }^{6}$. Because of the different languages, both higher education systems are quite closed systems, with only a limited number of students attending universities and colleges in the other region. Nevertheless, because of their long common history, both the Dutch-speaking and the French-speaking educational system are quite comparable in terms of enrollment policies.

All undergraduate higher education institutions in Flanders are public (Kelchtermans and Verboven, 2010). There are no entry barriers in higher and all high school graduates are allowed to start at all programs in higher education, regardless of their specific high school degree (Cantillon and Declercq, 2012) ${ }^{7}$. This leads to low success rates in the first year in higher education and many students drop out or switch to another program after the first year of study (Declercq and Verboven, 2014). Tuition fees are low (approximately 600 euro $^{8}$ in academic year 2013-2014) and cover only $3 \%$ of the total costs of higher education (Cantillon et al., 2006). Students can receive a scholarship if the income of the parents is below a certain threshold. The amount of the subsidy depends on the income of the parents. In contrast to other countries such as the U.K., there is no study loan system in Belgium. Most parents pay for the higher education studies of their children ${ }^{9}$.

The implementation of the Bachelor Master structure in the academic year 2004-2005 changed the organization of higher education In Flanders. Bachelor and master programs ${ }^{10}$ are offered at 2 types of institutions. Universities offer academic programs and colleges offer both academic and professional programs. Academic programs consist of 2 cycles, a 3 year bachelor program followed by a 1 or 2 year master program. Professional programs only consist of a 3 year bachelor program. There are several university and college campuses in Flanders.

\footnotetext{
${ }^{5}$ We only discuss institutional aspects that are relevant for the rest of the paper. Dassen and Luijten-Lub (2007) and De Ro (2008) provide more detailed information about education in Flanders.

${ }^{6} \mathrm{~A}$ small minority of the Dutch-speaking part (about 10\%) also lives in Brussels. There is also a small German-speaking part in Belgium, located in the East (about $0.6 \%$ of the population).

${ }^{7}$ The government only imposes entry exams for a very limited number of programs, such as medicine and dentistry at university.

${ }^{8}$ If the parents' income is low, students pay a lower tuition fee of 100 euro.

${ }^{9}$ It is possible for students to get a living wage to cover the costs of living and studying. However, this option is only available for students who have no access to other sources of financing (POD Maatschappelijke Integratie, 2014).

${ }^{10}$ Higher education institutions can also offer postgraduate programs, bridging programs, advanced master programs and doctoral programs. In this paper, we only focus on enrollment of high school graduates in academic and professional bachelor programs.
} 


\subsection{A first look at the data}

We combine 2 rich datasets provided by the Flemish Ministry of Education and Training. We observe gender, age, high school background and socio-economic status of all high school graduates eligible for higher education in 2008. We also observe detailed information on the students' locations ${ }^{11}$, from which it is possible to compute travel costs to all study options. We combine this dataset with a dataset of all students in higher education ${ }^{12}$.

In Table 1, we represent choices of the high school graduates of academic year 20072008 in Flanders. A total of 57,586 pupils graduated from high school and were eligible to start higher education. From these high school graduates, $69.8 \%$ actually enroll in higher education: $23.8 \%$ start at university and respectively $8.3 \%$ and $37.8 \%$ choose for an academic program or a professionally oriented program at college.

In the following rows of the table, we show that participation decisions differ according to gender, age at graduation from high school, high school background and socio-economic status. Males are less likely to participate in higher education: $65.4 \%$ of male high school graduates continue studying, compared with $73.9 \%$ of the female high school graduates. Males are also less likely to choose for university and professional college programs, but are more likely to choose for academic college programs. Pupils who graduate from high school without study delay, typically at the age of 18, are more likely to participate in higher education (78.4\% versus $51.1 \%$ ). This effect is strongest for academic programs, especially at university $(31.1 \%$ of the pupils without study delay start university, versus only $7.7 \%$ of the students with a study delay).

High school background also plays a major role in the study decisions. There are 4 types of programs in secondary education: general secondary education, technical secondary education, artistic secondary education and vocational secondary education. Programs in general secondary education provide pupils with a theoretical background and prepare them for higher education. In general secondary education, pupils can choose for various combinations of mathematics, classical languages, sciences, economics, modern languages and/or humanities. Programs in technical secondary education provide students with a theoretical and technical background to prepare them for professional higher education or the labor market. We aggregate the several programs in technical secondary education in 5 categories: business, technical sciences, social-technical sciences, technics and all other programs. Pro-

\footnotetext{
${ }^{11}$ We observe the location of the students at the level of the statistical sector. In Belgium, each municipality is divided into several statistical sectors.

${ }^{12}$ The student dataset contains information of all students who first registered for a program in higher education in 2008 or 2009. From the 57586 high school graduates, 39052 students start in higher education in academic year 2008-2009, while another 1158 students do not immediately start in higher education after graduating from high school but enter higher education with 1 year of delay.
} 
grams in artistic secondary education prepare pupils for a profession or higher education. Programs in vocational secondary education prepare pupils for the labor market, but they can also start at college or university ${ }^{13}$.

Pupils from general secondary education are most likely to participate in higher education: $53.2 \%$ choose for university programs, $12.7 \%$ for academic college programs and $29.8 \%$ for professional college programs. Only $4.3 \%$ of general high school graduates choose for the drop-out option. Participation decisions differ between the several programs in general secondary education. ${ }^{14}$ Pupils graduating from programs in mathematics or classical languages are most likely to start at university. Pupils graduating from technical secondary education are most likely to choose for professional programs: $63.2 \%$ of graduates from technical high schools start at a professional bachelor program, while only 3.5\% start at university. Again, study decisions differ between the several programs. Pupils from artistic programs in secondary education also prefer to continue studying, while pupils graduating from vocational secondary education are most likely to choose for the drop-out option. Only $13.5 \%$ of graduates from vocational secondary education enrolls in higher education.

Finally, socio-economic status also influences participation and study decisions. We measure the socio-economic status of the student by the following variables: educational degree of the mother, language spoken at home, and the study grant in high school as a measure of household income. The study grant variable is our proxy for household income because lowincome families obtain a scholarship for children in secondary education. The educational degree of the mother has an important effect on study decisions. The higher the educational degree of the mother, the higher the participation rates. If the mother has a degree in higher education, $40.2 \%$ of the students choose for a program at university, while only $9.6 \%$ do so if the mother has not finished secondary education. This gap is smaller for academic programs at college and has disappeared for professional programs at college. Pupils who speak Dutch at home are more likely to participate in higher education. This effect is similar for all options in higher education. Students from low-income families are less likely to participate in higher education: $25.8 \%$ of the high-income students start at university, compared with only $16.1 \%$ of the low-income students. However, low-income students are proportionally more represented at professional bachelor programs at college.

\footnotetext{
${ }^{13}$ Pupils who graduate from vocational secondary education have to complete an extra year of high school before they are allowed to enroll for programs in higher education.

${ }^{14}$ We aggregate similar programs in general and technical secondary education into the options represented in table 1.
} 
Table 1: Enrollment in higher education

\begin{tabular}{|c|c|c|c|c|}
\hline Characteristics & university & acad college & prof college & total \\
\hline All pupils & 23.8 & 8.3 & 37.8 & 69.8 \\
\hline \multicolumn{5}{|l|}{ Gender } \\
\hline male & 21.5 & 10.2 & 33.8 & 65.4 \\
\hline female & 25.9 & 6.5 & 41.5 & 73.9 \\
\hline \multicolumn{5}{|l|}{ Age } \\
\hline no study delay & 31.1 & 9.5 & 37.8 & 78.4 \\
\hline study delay & 7.7 & 5.6 & 37.8 & 51.1 \\
\hline \multicolumn{5}{|l|}{ High school background } \\
\hline general HS & 53.2 & 12.7 & 29.8 & 95.7 \\
\hline clas + math & 84.0 & 7.0 & 5.6 & 96.6 \\
\hline clas + lang & 69.9 & 10.7 & 14.9 & 95.5 \\
\hline sci + math & 66.2 & 16.5 & 13.8 & 96.5 \\
\hline math + lang & 48.4 & 15.5 & 31.1 & 95.0 \\
\hline econ + math & 53.6 & 19.3 & 24.1 & 97.0 \\
\hline econ + lang & 28.5 & 15.8 & 51.1 & 95.4 \\
\hline human & 29.3 & 6.6 & 58.6 & 94.5 \\
\hline technical HS & 3.5 & 5.8 & 63.2 & 72.5 \\
\hline business & 5.0 & 4.9 & 76.9 & 86.8 \\
\hline $\operatorname{sci}+$ tech & 9.5 & 22.4 & 59.5 & 91.4 \\
\hline social + tech & 2.2 & 2.4 & 81.9 & 86.5 \\
\hline technics & 0.6 & 3.8 & 46.7 & 51.2 \\
\hline other tech & 2.9 & 2.9 & 57.4 & 63.2 \\
\hline artistic HS & 9.5 & 37.0 & 39.9 & 86.4 \\
\hline vocational HS & 0.3 & 0.6 & 12.7 & 13.5 \\
\hline \multicolumn{5}{|l|}{ Socio economic background } \\
\hline mother no SE degree & 9.6 & 4.5 & 35.7 & 50.2 \\
\hline mother SE degree & 16.9 & 7.3 & 41.6 & 34.2 \\
\hline mother HE degree & 40.2 & 11.7 & 34.9 & 13.2 \\
\hline dutch at home & 23.9 & 8.3 & 38.1 & 29.6 \\
\hline no dutch at home & 21.3 & 7.1 & 31.8 & 39.8 \\
\hline study grant in HS & 16.1 & 7.0 & 40.0 & 36.9 \\
\hline no study grant in HS & 25.8 & 8.6 & 37.2 & 28.4 \\
\hline Total & 13691 & 4760 & 21759 & 17376 \\
\hline
\end{tabular}

Note: Percentage of high school graduates of 2008 who choose for each option, based on own calculations

From Table 1, we see that students from socially disadvantaged backgrounds are less likely to participate in higher education. This effect is strongest for two-cycle, academic bachelor programs at university. Carneiro and Heckman (2002) provide two possible expla- 
nations for the low participation of these students. The first interpretation is that students from low-income families are credit constrained and invest less in education. Their second interpretation emphasizes the long-run factors associated with socio-economic background. Socio-economic status influences children's preferences for education and ability. Better family resources stimulate the cognitive and noncognitive skills of children. Dahl and Lochner (2012) and Lundborg et al (2014) show that respectively family income and parental education significantly affect cognitive and non-cognitive skills of their children.

Table 2: Socio-economic status and high school outcomes

\begin{tabular}{|c|c|c|c|}
\hline Characteristics & & disadvantaged background & advantaged background \\
\hline \multicolumn{4}{|l|}{ Age } \\
\hline & no study delay & 59.6 & 74.1 \\
\hline & study delay & 40.4 & 25.9 \\
\hline \multicolumn{4}{|c|}{ High school background } \\
\hline & general HS & 27.6 & 50.6 \\
\hline & clas + math & 3.0 & 8.4 \\
\hline & clas + lang & 2.5 & 5.2 \\
\hline & sci + math & 5.3 & 12.6 \\
\hline & math + lang & 2.3 & 4.5 \\
\hline & econ + math & 1.7 & 2.9 \\
\hline & econ + lang & 6.8 & 9.4 \\
\hline & human & 5.9 & 7.7 \\
\hline & technical HS & 36.8 & 32.8 \\
\hline & business & 8.7 & 6.6 \\
\hline & sci + tech & 3.6 & 4.3 \\
\hline & social + tech & 5.5 & 5.1 \\
\hline & technics & 8.4 & 7.3 \\
\hline & other tech & 10.6 & 9.5 \\
\hline & artistic HS & 2.2 & 2.2 \\
\hline & vocational HS & 33.5 & 14.4 \\
\hline Total & & 21,755 & 35,831 \\
\hline
\end{tabular}

Note: High school outcomes are expressed as a percentage of high school graduates. High school outcomes add up to $100 \%$ for age and high school background type (general, technical, artistic, vocational). Within the first two types (general and technical), we also distinguish between specific program.

In Table 2, we provide evidence for the second explanation of Carneiro and Heckman (2002). We find that high school outcomes differ according to their socio-economic status. 
We split the sample of high school graduates in two groups according to socio-economic background. We define a student as coming from a socially disadvantaged background if he or she satisfied at a minimum one of the following criteria: the mother has no degree in at least secondary education; the language spoken at home is not Dutch; or a study grant was granted in secondary school.

Students from socially disadvantaged backgrounds are less likely to graduate from high school without study delay. Only $59.6 \%$ of disadvantaged students graduate without delay, while $74.1 \%$ of the other students graduate at the age of 18 . Students from socially disadvantaged backgrounds are also less likely to graduate from programs in general secondary education that prepare students for higher education. Only $27.6 \%$ of students from socially disadvantaged backgrounds graduate from general secondary education, while 50.6 of advantaged students graduate from a general high school program. This gap is even larger in high school programs that focus on mathematics, classical languages or sciences. Students with a lower level of socio-economic capital are twice as likely to graduate from vocational secondary education. Declercq and Verboven (2014) show that high school background is an important determinant of study decisions and success in higher education.

\section{$3 \quad$ Empirical analysis}

From the descriptive statistics, we see that socio-economic status is correlated with study decisions in higher education. Socio-economic status also determines previous schooling and therefore study decisions in higher education. In our empirical analysis, we allow for the following three channels through which socio-economic status can influence enrollment in higher education:

1. Sensitivity to the costs of higher education: Disadvantaged students are less likely to enroll in higher education because they are more sensitive to the costs of education.

2. Preferences for higher education: Disadvantaged students are less likely to enroll because they have lower tastes for education or lower expectations about the returns.

3. Academic ability: Disadvantaged students are less likely to enroll because they have less favorable high school outcomes.

We use a discrete choice approach to analyze the impact of these channels on enrollment and study decisions. We model both the choice between the type of program and the campus. First, we specify the equation for the utility of studying and the equation for the costs of education. Then, we estimate three discrete choice models: a conditional logit model, a nested 
logit model and a random coefficients model, where we allow for unobserved heterogeneity in preferences and cost sensitivity and unrestricted substitution patterns.

\subsection{Utility of studying}

After graduating from high school, students can choose to continue education or to start working. A student $i$ chooses an option $j \in J$, with $J$ the set of choice alternatives to maximize the utility of studying. The utility of studying $U_{i j}$ depends on gender and high school background $X_{i}$, socio-economic background $S_{i}$, and the costs of studying $C_{i j}$ and is given by

$$
\begin{aligned}
U_{i j}\left(X_{i}, S_{i}, C_{i j}\right) & =\alpha_{i j}+\beta_{j} X_{i}+\gamma_{j} S_{i}+\delta_{i} C_{i j}+\phi C_{i j} S_{i}+\varepsilon_{i j} \\
& =V_{i j}\left(X_{i}, S_{i}, C_{i j}\right)+\varepsilon_{i j}
\end{aligned}
$$

where $V_{i j}\left(X_{i}, S_{i}, C_{i j}\right)$ represents the deterministic part of utility and $\varepsilon_{i j}$ represents the unobserved factors affecting the utility of studying. We allow for an individual alternative specific constant term $\alpha_{i j}$. This takes into account that students differ in unobserved preferences for the several study options. Observed characteristics also influence the utility of studying. $\beta_{j}$ measures the impact of gender and high school background $X_{i}$ on the utility of studying. Socio-economic status $S_{i}$ determines the preferences for education through $\gamma_{j}$ (the second channel through which socio-economic status influences study decisions). The impact of socio-economic status differs between the several options $j . \delta_{i}$ measures the sensitivity to the costs of education. Students are heterogeneous in their sensitivity to costs. We test whether socio-economic status influences the sensitivity to costs by interacting the socio-economic variables with the cost variable. $\phi$ measures the cost-effect of socio-economic status on enrollment (the third channel through which socio-economic status influences study decisions)

\subsection{Costs of education}

The costs for student $i$ in option $j$ are given by equation (2). They consist of the tuition fee $F_{i j}$, travel costs $T_{i j}$, and the study grant received in higher education $G_{i j}$. The costs are given by

$$
C_{i j}=F_{i j}+T_{i j}\left(d_{i j}, t_{i j}, R_{i j}\right)-G_{i j}
$$

Tuition fees and study grants in higher education depend on household income. The lower the household income, the higher the amount of the study grant. Students who receive 
a subsidy also have to pay a lower tuition fee ${ }^{15}$. We specify a similar travel cost function as in Kelchtermans and Verboven (2010) where travel costs $T_{i j}\left(d_{i j}, t_{i j}, R_{i j}\right)$ depend on the distance $\left(d_{i j}\right)$ between the home municipality of the student and the college or university campus, travel time $t_{i j}$ and on the costs of going on residence $R_{i j}$. The annual travel costs for students who do not go on residence are given by

$$
T_{i j}=75 d_{i j}+42 t_{i j}
$$

As in Kelchtermans and Verboven (2010), We assume that students make 10 trips during 30 weeks at a transportation cost of 0.25 euros $/ \mathrm{km}$ and an opportunity cost of time of 8.36 euro/hour ${ }^{16}$. Students who go on residence, save a fraction $\pi$ of the trips but pay an extra annual cost on rent $R_{i j}$. Students who obtain a study grant, pay lower rents. The cost of going on residence is given by

$$
T_{i j}=R_{i j}+(1-\pi)\left(75 d_{i j}+42 t_{i j}\right) .
$$

In our dataset, we do not observe whether students decide to commute or go on residence.

Therefore, we assume that students go on residence if the costs of commuting exceed the costs of going on residence ${ }^{17}$.

To compute the expected study grant $G_{i j}$ for all high school graduates, we face the following two problems: First, we only observe whether a student obtains a study grant and not the exact amount of the grant $G_{i j}$. Second, we only observe the subsidy variable for students who start in higher education and not for students who do not participate. This implies that we need to impose some additional assumptions on the cost function to compute the amount of the subsidy for both students and outsiders.

Nielsen, Sorensen and Taber (2010) and Lundborg et al (2014) face similar problems and calculate the exact amount of the subsidy for students and outsiders based on the algorithm that the authorities used to compute the grants. As we do not observe family income, we assume that students who get a subsidy in higher education, obtain the average amount of

\footnotetext{
${ }^{15}$ In Flanders, tuition fees are already low (approximately 620 euro). Students who receive a scholarship have to pay a tuition fee of only 104 euro.

${ }^{16}$ This corresponds to the typical wage for student jobs (Jobdienst KU Leuven).

${ }^{17}$ Estimates of the annual cost of going on residence are available for the university of Ghent (Sociale dienst, UGent). Students without a study grant pay an annual rent of 3096 euro, while students with a study grant pay an annual rent of only 1764 euro for a room offered by the university. We assume that rental prices are similar in other cities.
} 
the subsidy given in higher education. The average subsidy in academic year 2008-2009, the year of our analysis, was 1726 euro for university programs and 1488 euro for college programs $^{18}$.

To predict the expected subsidy of non-participants, we use a dummy variable for whether a student received a grant in high school as a measure of household income. Low-income students obtain a subsidy in high school. We assume that pupils who choose for the drop-out option would receive a subsidy in higher education if they already obtained a subsidy in high school $^{19}$. Again, we assume that they would obtain the average subsidy in higher education.

\subsection{Estimation}

We use a mixed logit model to estimate the effect of socio-economic background on study decisions and cost sensitivity. After graduating from high school, a student chooses an option $j \in J$ to maximize utility, given by equation (1). We model the choice between the dropout option and 45 study alternatives in higher education. We define a study option as a type of program (university, academic college, professional college) at a specific campus. We normalize the utility of the professional bachelor program at college to zero.

Random coefficients or mixed logit models do not exhibit the independence from irrelevant alternatives assumption (Brownstone and Train, 1999). These models assume that $\varepsilon_{i j}$ is independently and identically type 1 extreme value distributed, but in addition allow for unobserved heterogeneity regarding the other parameters, which creates flexible substitution patterns between options. We estimate the mean effect of the variables and the standard deviation around the mean. We specify the probability $P_{i j}$ that individual $i$ chooses for option $j$ as follows

$$
P_{i j}=\int\left(\frac{e^{V_{i j}\left(X_{i}, S_{i}, C_{i j}\right)}}{\sum_{j^{\prime} \in J} e^{V_{i j^{\prime}}\left(X_{i}, S_{i}, C_{i j^{\prime}}\right)}}\right) f(\theta) d \theta,
$$

with $f(\theta)$ the normal density function of the random coefficients $\theta$. In the notation of equation (1), $\theta$ includes $\alpha_{i j}$ and $\delta_{i}$ because we allow for heterogeneity in preferences for the several study options $j$ and heterogeneity in the sensitivity to the costs of education. We assume that the effect of personal characteristics $X_{i}$, and socio-economic status $S_{i}$ is the same for all students.

Given the size of our dataset, where 57,586 students choose between 46 options, it is

\footnotetext{
${ }^{18}$ The Flemish Ministry of Education and Training provides data about the total amount of subsidies in higher education and the number of recipients. We computed the average subsidy in higher education.

${ }^{19}$ From the sample of participating students, we find that obtaining a study grant in high school is a good predictor of obtaining a study grant in higher education. The correlation between both is $72 \%$.
} 
not computationally feasible to estimate the model with the full dataset. We therefore use a random subsample of 30 percent of the students. As the choice probabilities, given by equation (5), have no closed form solution, we estimate the model with maximum simulated likelihood. We assume that the coefficients are drawn from a normal density function $f(\theta)$ to generate 100 draws of the coefficients for each student.

We also estimate two special cases of the mixed logit model. The first simplification is the conditional logit model. In this model, we do not allow for unobserved heterogeneity in the valuation of the alternative-specific constants, i.e. $\alpha_{i j}=\alpha_{j}$ in (1), and in the sensitivity to costs, i.e. $\delta_{i}=\delta$. The error term $\varepsilon_{i j}$ is still independently and identically type 1 extreme value distributed, but there is no other unobserved heterogeneity. The assumptions of this model are discussed in Train (2009). The probability $P_{i j}$ that student $i$ chooses option $j \in J$ is then given by

$$
P_{i j}=\frac{e^{V_{i j}\left(X_{i}, S_{i}, C_{i j}\right)}}{\sum_{j^{\prime} \in J} e^{V_{i j^{\prime}}\left(X_{i}, S_{i}, C_{i j^{\prime}}\right)}} .
$$

The independence of irrelevant alternatives assumption of the conditional logit model implies that the unobserved factors of utility are uncorrelated across alternatives. Increasing the utility of one option implies a proportional decrease in the probability of choosing for all other alternatives.

The second simplification of the random coefficients logit model is the nested logit model. This model relaxes the independence from irrelevant alternatives assumption and allows for more realistic substitution patterns. This model allows for correlation of the unobserved factors $\varepsilon_{i j}$ affecting utility within each nest. Kelchtermans and Verboven (2010) find that students perceive the higher education institutions and programs as close substitutes. We therefore specify a nested logit model with two nests: a no-study nest and a study nest. The study nest includes 45 study options in higher education. The no-study nest includes the drop-out option. As in Train (2009), the probability $P_{i j k}$ that individual $i$ chooses for option $j$ in nest $B_{k}$ is given by the nested logit model (7).

$$
P_{i j k}=\frac{e^{\left(V_{i j}\left(X_{i}, S_{i}, C_{i j}\right) / \lambda\right)}\left(\sum_{j^{\prime} \in B_{k}} e^{\left(V_{i j^{\prime}}\left(X_{i}, S_{i}, C_{i j^{\prime}}\right) / \lambda\right)}\right)^{\lambda-1}}{\sum_{n=1}^{2}\left(\sum_{j^{\prime} \in B_{n}} e^{\left(V_{i j^{\prime}}\left(X_{i}, S_{i}, C_{i j^{\prime}}\right) / \lambda\right)}\right)^{\lambda}} .
$$

The parameter $\lambda$ is a measure of the degree of independence in unobserved utility among the alternatives in nest $B_{k}$. The nested logit model can be viewed as an intermediate model between the other two models. On the one hand, the nested logit model is a generalization of the conditional logit model because it allows tastes for the alternatives with the nests 
(study versus no-study) to be correlated. There is perfect correlation if $\lambda=0$, and there is no correlation as in the conditional logit if $\lambda=1$. On the other hand, the nested logit is less general than the mixed logit: it allows for correlation between alternatives of the same nest, whereas the mixed logit allows for additional sources of unobserved heterogeneity in particular the sensitivity to travel costs.

\section{Empirical results}

We first discuss the estimation results of the three discrete choice models. We focus on the results of the mixed logit model because this model takes into account unobserved heterogeneity and allows for less restrictive substitution patterns than the other models. Then, we quantify the relative impact of the three channels through which socio-economic status influences enrollment in higher education.

\subsection{Demand estimation}

In Table 3, we present the results of the mixed logit model. The results of the conditional logit and the nested logit model are shown in Table A1 and A2 in Appendix. A comparison of the three models shows that unobserved heterogeneity is important, but the sign and significance levels of the other coefficients do not differ much between the several models. Our nested logit model in Table A2 is consistent with utility maximization for all possible values of the explanatory variables because the estimated value of the nesting parameter $\lambda$ is between 0 and 1 ( $\lambda=0.254$ with a standard error of 0.021 , implying strong correlation of preferences for the study options relative to the no-study alternative). The nested logit model also provides a better fit of the data in terms of the log likelihood. ${ }^{20}$ In the remainder of this section, we only describe the results of our mixed logit model because this model takes into account unobserved heterogeneity in preferences and cost sensitivity in a more flexible way, allowing for less restrictive substitution patterns.

From the results of the mixed logit model in Table 3, we first see that even after taking into account a lot of observed heterogeneity, such as gender and high school background $X_{i}$ and socio-economic background $S_{i}$, students significantly differ in unobserved preferences for the study options $\alpha_{j}$. The standard deviations of the random coefficients for the no-study

\footnotetext{
${ }^{20}$ We cannot compare the value of the reported log likelihood of the conditional logit and nested logit models with the log likelihood of the mixed logit model because the mixed logit model is estimated on a random sample of the data. However, when we compare the log likelihood of the mixed logit model with the values of the log likelihood of a conditional logit model and a nested logit model on a random sample of the same size, we see that the mixed logit model provides the best fit of the data.
} 
option, for the university study options and for academic college study options are all highly significant. Gender and age significantly affect study decisions in higher education. Males are more likely to choose for the non-study option relative to the reference category, a professional bachelor program at college. However, males who participate in higher education prefer to start at 2 cycle academic programs at college relative to 1 cycle professional programs at college. Pupils who graduate from high school with some years of study delay are more likely to choose for the drop-out option. If they decide to participate in higher education, they are most likely to choose for 1 cycle professional bachelor programs at college.

High school background determines choices in higher education. Students graduating from general, technical or artistic secondary education are less likely to choose for the dropout option compared to pupils from vocational secondary education. Students from programs in general secondary education are most likely to choose for 2 cycle academic programs at university or college. Students who studied mathematics, classical languages or sciences in high school have the strongest preference for university. We also distinguish between programs in technical secondary education. We find that students who studied technical sciences in high school prefer academic bachelor programs at college relative to professional bachelor programs at college. Most graduates from technical secondary education prefer academic or professional bachelor programs at college. We do not include interaction effects between programs in technical secondary education and university level programs, because only few students from technical, artistic or vocational programs start at university. Pupils graduating from artistic secondary education are most likely to choose for academic college programs.

Socio-economic status significantly determines study decisions after controlling for previous schooling. We measure the socio-economic status by the educational degree of the mother, language spoken at home and a dummy for whether a pupil received a subsidy in high school as a proxy for household income. A student whose mother has no degree in higher education is more likely to choose for the drop-out option. The degree of the mother also influences choices in higher education. Students whose mother has no degree in higher education are less likely to start at 2 cycle programs at college or university relative to professional bachelor programs at college that consist of 1 cycle. This effect is stronger if the mother has no degree in secondary education. Pupils who do not speak Dutch at home are more likely to choose for the drop-out option. However, if they participate in higher education, they are more likely to choose for 2 cycle programs at university relative to 1 cycle professional college programs. We also find that household income determines the decision to participate but not the choice between the several programs. Students whose household income is below a certain threshold are more likely to choose for the drop-out option. 
Table 3: Random coefficients model

\begin{tabular}{|c|c|c|c|c|c|c|}
\hline \multirow[b]{3}{*}{ Variables } & \multirow{2}{*}{\multicolumn{2}{|c|}{ no study option }} & \multicolumn{4}{|c|}{ study options } \\
\hline & & & \multicolumn{2}{|c|}{ university $^{a}$} & \multicolumn{2}{|c|}{ academic college $^{a}$} \\
\hline & Coef. & St. error & Coef. & St. error & Coef. & St. error \\
\hline \multicolumn{7}{|l|}{ constant $\left(\alpha_{j}\right)$} \\
\hline mean & $5.659^{* * *}$ & $(0.768)$ & $-11.817^{* * *}$ & $(1.622)$ & $-13.013^{* * *}$ & $(1.737)$ \\
\hline st. deviation & $8.986^{* * *}$ & $(0.971)$ & $8.652^{* * *}$ & $(1.058)$ & $7.355^{* * *}$ & $(0.924)$ \\
\hline \multicolumn{7}{|c|}{ Gender and high school background $\left(\beta_{j}\right)$} \\
\hline male & $1.164^{* * *}$ & $(0.289)$ & 0.239 & $(0.263)$ & $2.497 * * *$ & $(0.370)$ \\
\hline study delay & $2.975^{* * *}$ & $(0.395)$ & $-1.538^{* * *}$ & $(0.390)$ & $-0.903^{* * *}$ & $(0.314)$ \\
\hline \multicolumn{7}{|l|}{ general $\mathrm{HS}^{b}$} \\
\hline clas + math & $-16.311^{* * *}$ & $(2.154)$ & $25.247^{* * *}$ & $(2.953)$ & $9.401^{* * *}$ & $(1.189)$ \\
\hline clas + lang & $-19.635^{* * *}$ & $(2.532)$ & $19.880^{* * *}$ & $(2.376)$ & $8.891^{* * *}$ & $(1.193)$ \\
\hline sci + math & $-19.594^{* * *}$ & $(2.228)$ & $20.106^{* * *}$ & $(2.336)$ & $10.313^{* * *}$ & $(1.255)$ \\
\hline math + lang & $-20.343^{* * *}$ & $(2.334)$ & $14.491^{* * *}$ & $(1.785)$ & $7.849^{* * *}$ & $(1.135)$ \\
\hline eco + math & $-24.413^{* * *}$ & $(2.754)$ & $17.246^{* * *}$ & $(2.101)$ & $8.758^{* * *}$ & $(1.256)$ \\
\hline eco + lang & $-22.895^{* * *}$ & $(2.484)$ & $9.713^{* * *}$ & $(1.236)$ & $6.725^{* * *}$ & $(0.992)$ \\
\hline human & $-22.118^{* * *}$ & $(2.381)$ & $10.368^{* * *}$ & $(1.317)$ & $3.414^{* * *}$ & $(0.788)$ \\
\hline \multicolumn{7}{|l|}{ technical $\mathrm{HS}^{b}$} \\
\hline business & $-20.157^{* * *}$ & $(2.133)$ & - & - & 0.361 & $(0.671)$ \\
\hline $\mathrm{sci}+$ tech & $-21.900^{* * *}$ & $(2.367)$ & - & - & $7.341^{* * *}$ & $(1.102)$ \\
\hline social + tech & $-18.728^{* * *}$ & $(1.995)$ & - & - & -1.304 & $(0.856)$ \\
\hline technics & $-10.714^{* * *}$ & $(1.158)$ & - & - & 0.853 & $(0.700)$ \\
\hline other tech & $-12.871^{* * *}$ & $(1.384)$ & - & - & $1.152^{*}$ & $(0.659)$ \\
\hline artistic $\mathrm{HS}^{b}$ & $-17.171^{* * *}$ & $(2.001)$ & - & - & $12.219^{* * *}$ & $(1.576)$ \\
\hline \multicolumn{7}{|c|}{ Socio-economic status $\left(\gamma_{j}\right)$} \\
\hline mother no SE degree ${ }^{c}$ & $2.309^{* * *}$ & $(0.475)$ & $-2.864^{* * *}$ & $(0.522)$ & $-1.435^{* * *}$ & $(0.409)$ \\
\hline mother SE degree ${ }^{c}$ & $1.455^{* * *}$ & $(0.370)$ & $-2.111^{* * *}$ & $(0.362)$ & $-0.833^{* * *}$ & $(0.286)$ \\
\hline no dutch at home & $2.243^{* * *}$ & $(0.540)$ & $2.381^{* * *}$ & $(0.626)$ & $1.613^{* * *}$ & $(0.564)$ \\
\hline low income & $0.766^{* *}$ & $(0.330)$ & 0.214 & $(0.345)$ & -0.150 & $(0.321)$ \\
\hline
\end{tabular}

Note: standard errors in parentheses; ${ }^{* * *} \mathrm{p}<0.01, * * \mathrm{p}<0.05, * \mathrm{p}<0.1$

${ }^{a}$ Base category $=$ professional college program

${ }^{b}$ Base category $=$ technical + artistic + vocational secondary education for university, vocational secondary education for college

${ }^{c}$ Base category $=$ mother has a degree in higher education 
Table 3 (continued): Random coefficients model

\begin{tabular}{|c|c|c|}
\hline Variables & Coef. & St. errol \\
\hline \multicolumn{3}{|l|}{ Cost sensitivity $(\delta)$} \\
\hline \multicolumn{3}{|l|}{ constant } \\
\hline mean & $-0.944^{* * *}$ & $(0.015)$ \\
\hline st. deviation & $0.196^{* * *}$ & $(0.030)$ \\
\hline \multicolumn{3}{|c|}{ Cost sensitivity and socio-economic status $(\phi)$} \\
\hline mother no SE degree ${ }^{c}$ & $-0.192^{* * *}$ & $(0.027)$ \\
\hline mother SE degree ${ }^{c}$ & $-0.134^{* * *}$ & $(0.019)$ \\
\hline no dutch at home & $-0.151^{* * *}$ & $(0.049)$ \\
\hline low income & $-0.341 * * *$ & $(0.030)$ \\
\hline Log likelihood & \multicolumn{2}{|c|}{-37188.73} \\
\hline
\end{tabular}

Finally, students are sensitive to the costs of education and differ in their sensitivity to costs. Furthermore, socio-economic status determines the sensitivity to the costs of education. A student whose mother has no degree in secondary education or does not speak Dutch at home is more sensitive to the costs of education. Low-income students are also more sensitive to the costs of education.

We find evidence for both interpretations of Carneiro and Heckman (2002) for the low participation of students with weaker socio-economic characteristics. The first interpretation is that students from low-income families are credit constrained and invest less in education. We find that students with a lower level of socio-economic capital are indeed more affected by costs in their study decision. The second interpretation emphasizes the long-run effects of socio-economic background, such as preferences for education and acquired ability in high school. We find that socio-economic status has a direct impact on the utility of studying and an indirect impact through high school outcomes. We will now move on to quantifying the importance of these three channels.

\subsection{Decomposition of the enrollment gap}

Based on our previous results, we can now quantify the relative importance of the three channels through which socio-economic background influences enrollment in higher education. We simulate the effect of relaxing the impact of socio-economic status by predicting study decisions of students as if the group of disadvantaged students would have similar 
characteristics as the advantaged students. As in Table 2, we define a student as coming from a socially disadvantaged background if his or her mother has no degree in secondary education or the language spoken at home is not Dutch or the student obtained a subsidy in secondary school. Students who received a subsidy in higher education have a low household income.

In Table 4, we simulate how total enrollment in higher education would increase if disadvantaged students would have the same characteristics as advantaged students. We only represent the outcomes of the mixed logit model. Outcomes of the conditional and nested logit model are represented in table A3 in Appendix. To quantify the impact of the cost and preference channel, we assume that the language at home and the subsidy in secondary education have no effect on enrollment. This is the case for the advantaged students. As the group of advantaged students consists of both students with a mother with only a high school degree and students with a mother with a degree in higher education, we cannot simply set the effect of the diploma of the mother to zero for disadvantaged students: we would then overpredict the effect of socio-economic status. We therefore randomly assign students of disadvantaged backgrounds to one of these two groups according to the fraction of students in the advantaged group. ${ }^{21}$ For example, $49 \%$ of the advantaged students has a mother with only a high school degree and $51 \%$ has a mother with a degree in higher education. In our simulation we then randomly give $49 \%$ of the disadvantaged students a mother with a high school degree and $51 \%$ of the disadvantaged a mother with a degree in higher education. To quantify the impact of the academic ability channel, we give students from disadvantaged backgrounds the same favorable high school outcomes as the advantaged students. Again, we randomly assign high school programs to disadvantaged students according to the fraction of students in the advantaged group.

First, we simulate the effect of separately relaxing the impact of the cost sensitivity channel. In this case, costs have the same impact on disadvantaged as on advantaged students. Disadvantaged students still differ in preferences and academic ability from advantaged students. The mixed logit model predicts that total enrollment would increase by 0.4 percentage points. This increase in enrollment can be entirely attributed to an increase in enrollment at college programs. Note that this cost sensitivity effect is similar in the nested logit model (0.5 percentage points), but much larger in the conditional logit model which does not allow for any unobserved heterogeneity (+1.4 percentage points).

Second, we simulate the effect of separately relaxing the impact of the preference channel.

\footnotetext{
${ }^{21}$ When randomly assigning more favourable characteristics to the disadvantaged students, the predicted changes in enrollment differ slightly for every random draw of characteristics. Therefore, we repeated the predictions 50 times and represent the average predicted increase in enrollment in table 4.
} 
Students from disadvantaged backgrounds then have the same preferences, indirect costs or expectations as advantaged students. In this case, total enrollment would increase by 1.8 percentage points, again mainly because of more enrollment at professional college programs $(+1.1$ percentage points). Results are similar in the nested logit model $(+1.5$ percentage points) but again much larger in the conditional logit model which ignores unobserved heterogeneity (+4.7 percentage points).

Table 4: Decomposing the impact of socio-economic background

\begin{tabular}{lcccc}
\hline & univ & acad coll & prof coll & total \\
\hline Observed choices & 23.8 & 8.3 & 37.8 & 69.8 \\
Status quo (mixed logit model) & 23.6 & 8.4 & 37.9 & 69.9 \\
& & & & +0.4 \\
Relaxing the impact of socio-economic background & & +0.4 & +1.8 \\
Cost effect & +0.0 & +0.0 & +1.1 & +6.5 \\
Preference effect & +0.5 & +0.3 & +0.9 & +1.5 \\
Ability effect & +4.5 & +1.1 & +1.4 & +8.4 \\
All effects & +5.5 & & & +1.5 \\
\hline
\end{tabular}

Note: Observed and predicted outcomes are expressed as percentages of 2008 high school graduates.

The effects of the counterfactuals are expressed as percentage point changes relative to the predicted choice probabilities.

Third, we simulate the effect of separately relaxing the academic ability channel. We give students from disadvantaged backgrounds similar high school outcomes as advantaged students. We find that total enrollment in higher education would increase by 6.5 percentage points. Interestingly, this effect is now mainly due to higher enrollment at university programs $(+4.5$ percentage points). Results are similar in the other two models.

Finally, we simulate the effect of simultaneously relaxing the impact of all three channels. We find that total enrollment in higher education would increase by 8.4 percentage points, half of which is due to a higher enrollment at universities. The nested logit model predicts a similar increase of 8.6 percentage points, while the conditional logit model predicts a larger increase of 10.9 percentage points. We conclude that academic ability $(+6.5 \%)$ and preferences $(+1.8 \%)$ are more important than costs $(+0.4 \%)$ in explaining the participation gap of disadvantaged students. These findings are consistent with Carneiro and Heckman (2002) who find that long run family effects, shaping academic ability and tastes for education, are more important in explaining the low participation of students from socially disadvantaged backgrounds than short term credit constraints. 


\section{$5 \quad$ Policy counterfactuals}

We can use the results on the cost sensitivity channel to simulate the impact of alternative tuition fee policies. Tuition costs only cover approximately $3 \%$ of the total costs of higher education in Flanders (Cantillon et al., 2006), and there is increasing pressure to raise tuition fees in many countries to meet budgetary constraints. Some countries, such as the U.K., have recently already raised tuition fees to increase the private contribution to the total costs of higher education. It is therefore highly relevant to assess the impact of tuition fee increases on enrollment. In Table 5, we represent the predicted changes in enrollment of three alternative tuition fee policies. We again only present the results of the mixed logit model because this model allows for less restrictive substitution patterns. Results of the nested logit model and the conditional logit model are shown in Table A4 and A5 in Appendix.

We first simulate the impact of a uniform 1000 euro cost increase for all students in all programs in higher education. Total enrollment in higher education would decrease by 2.3 percentage points. Participation of the students from socially disadvantaged backgrounds would decrease by a higher amount of 3 percentage points, while participation of advantaged students decreases by only 1.9 percentage points. This is because of our earlier finding that disadvantaged students are more sensitive to costs, as shown in Table 3. The nested logit model in Table A4 in Appendix again predicts similar effects as the mixed logit model: there is a slightly larger decrease of 3.6 percentage points for disadvantaged students and of 2.2 percentage points for advantaged students. In contrast, the conditional logit model in Table A5 in Appendix strongly overpredicts the effect of cost increases on the enrollment decisions, respectively -11.6 and -6.8 percentage points. ${ }^{22}$

Given that a uniform tuition fee increase has a stronger negative impact on enrollment of students from socially disadvantaged background, it is interesting to ask whether discriminatory tuition fee increases can improve enrollment outcomes. We therefore simulate the impact of two alternative budgetary-neutral tuition fee policies. Both policies raise tuition fees of advantaged students by 1000 euro (as before), but at the same time implement a subsidy to disadvantaged students in such a way that total government expenditures do not increase. The policies differ in the definition of disadvantaged students who are entitled to receive the subsidy. The first policy grants a 1500 euro extra subsidy for low income

\footnotetext{
${ }^{22}$ Kelchtermans and Verboven (2010) also find that the conditional logit model strongly overpredicts the effects of costs as compared with the nested logit model. Intuitively, both the mixed logit and nested logit model incorporate unobserved heterogeneity, which allows for less restrictive substitution patters. Both models imply that students are more sensitive to costs in their decision where and what to study than in their participation decision. The conditional logit model instead constrains students to be equally responsive to costs in their enrollment as in their study decision.
} 
students, i.e. all students who already obtain a subsidy in the status quo. ${ }^{23}$

Table 5: The impact of alternative tuition fee policies

\begin{tabular}{lcccc}
\hline & univ & acad coll & prof coll & total \\
\hline Observed choices & & & & \\
all students & 23.8 & 8.3 & 37.8 & 69.8 \\
advantaged students & 29.5 & 9.5 & 38.2 & 77.2 \\
$\quad$ disadvantaged students & 14.3 & 6.2 & 37.1 & 57.6
\end{tabular}

Mixed logit model

Status quo

$\begin{array}{lcccc}\text { all students } & 23.6 & 8.4 & 37.9 & 70.0 \\ \text { advantaged students } & 29.0 & 9.8 & 38.3 & 77.0 \\ \text { disadvantaged students } & 14.8 & 6.2 & 37.4 & 58.4 \\ \text { niform tuition fee increase }{ }^{a} & & & & -2.3 \\ \text { all students } & -0.2 & -0.2 & -2.0 & -1.9 \\ \text { advantaged students } & -0.2 & -0.2 & -1.6 & -3.0 \\ \text { disadvantaged students } & -0.2 & -0.2 & -2.6 & \end{array}$

Cost neutral tuition policy ${ }^{b}$ with subsidy for low income students

$\begin{array}{lllll}\text { all students } & -0.1 & -0.1 & -0.4 & -0.5 \\ \text { advantaged students } & -0.2 & -0.1 & -1.3 & -1.7 \\ \text { disadvantaged students } & +0.1 & +0.1 & +1.2 & +1.3\end{array}$

Cost neutral tuition policy ${ }^{c}$ with subsidy for disadvantaged students

\begin{tabular}{lcccc} 
all students & -0.1 & -0.0 & +0.0 & -0.1 \\
advantaged students & -0.2 & -0.2 & -1.6 & -1.9 \\
disadvantaged students & +0.2 & +0.2 & +2.6 & +3.0 \\
\hline
\end{tabular}

Note: Observed and predicted outcomes are expressed as percentages of 2008 high school graduates.

Outcomes of the counterfactual policies are expressed as percentage point changes relative to the status quo.

${ }^{a}$ Tuition fee increase of 1000 euro for all students in all options in higher education.

${ }^{b}$ Subsidy of 1500 euro for low income students financed by a 1000 euro cost increase for other students

${ }^{c}$ Subsidy of 1000 euro for disadvantaged students financed by a 1000 euro cost increase for advantaged students.

Table 5 shows that this policy slightly decreases total enrollment in higher education (-0.5 percentage points), but it increases enrollments of students from disadvantaged backgrounds

\footnotetext{
${ }^{23}$ We computed the maximum amount of the subsidy, rounded off to 100 euro, financed by a cost increase of 1000 euro for high income students under the constraint that total costs for the government may not increase. The amount of the subsidy differs between the three models because of the different sensitivity to costs.
} 
by 1.3 percentage points. ${ }^{24}$

The second budgetary-neutral alternative policy does not restrict subsidies to low income students, but extends the benefits to other disadvantaged students. ${ }^{25}$ Under this scenario, more students will obtain a subsidy, so the subsidy is now limited to 1000 euro to keep total government expenditures at the current level. This alternative policy has almost no effect on total enrollment (-0.1 percentage points), but it increases enrollment of disadvantaged students by 3 percentage points. ${ }^{26}$ This policy therefore has a lower impact on total enrollment and it leads to a larger decrease in the enrollment gap between advantaged and disadvantaged students than the first scenario. Hence, the government may better extend subsidies to all disadvantaged students instead of only subsidizing the low income students.

\section{Conclusion}

We have analyzed the impact of socio-economic status on enrollment and study decisions in higher education in Flanders. Descriptive statistics show that students from socially disadvantaged backgrounds are less likely to participate. The participation gap is largest at universities. We distinguish between three channels through which socio-economic status influences enrollment and study decisions. First, students from disadvantaged backgrounds participate less in higher education because they are more sensitive to the costs of education. Second, they are less likely to enroll because of lower preferences for education. This preference effect captures the fact that disadvantaged students have lower tastes for education, higher indirect costs of studying or lower expectations about the returns of the investment. Third, students from disadvantaged backgrounds have lower academic ability when they graduate from high school, which makes them less likely to enroll.

To empirically distinguish between these three channels, we estimated a mixed logit model of program and institution choice for all high school graduates in Flanders in 2008. The mixed logit model allows for unobserved heterogeneity regarding the valuation of the study options (university versus college versus no-study) and regarding the sensitivity to costs, which implies flexible substitution patterns. We compare the results with a nested

\footnotetext{
${ }^{24}$ The effects of this budget neutral policy are similar in the nested logit model with a 1400 euro subsidy for low income students financed by a 1000 euro cost increase for other students. The conditional logit model predicts larger decreases in enrollment. Under the budget neutral scenario, the amount of the subsidy is limited to 600 euro because this model predicts larger effects of cost changes.

${ }^{25}$ Under this alternative policy, also students whose mother has no degree in high school or students who do not speak Dutch at home obtain a subsidy.

${ }^{26}$ We find similar effects in the nested logit model but a decrease in enrollment in the conditional logit model. In this model, the amount of the subsidy is limited to 500 euro to keep the total costs for the government at the same level.
} 
logit model, where we allow for more limited correlation of the unobserved factors within each nest, and a simple conditional logit model that forces students to be equally responsive to costs in their enrollment as in their study decisions. We find that it is important to control for unobserved heterogeneity because students differ in their unobserved preferences and cost sensitivity and that socio-economic status significantly affects study decisions and the sensitivity to costs.

We then quantify the impact of the three channels through which socio-economic status influences enrollment in higher education. To accomplish this, we predict the study decisions of students as if the group of disadvantaged students would have similar characteristics as the advantaged students. Consistent with the findings in Carneiro and Heckman (2002), we find that the long term effects of socio-economic background, such as preferences for education and acquired academic ability in high school, dominate the short term cost effect. The mixed logit model predicts that relaxing the three effects increases total enrollment in higher education by 8.4 percentage points. Relaxing the effect on (acquired) ability and preferences increases participation by respectively 6.5 and 1.8 percentage points, while relaxing the cost sensitivity effect leads to an increase in participation of only 0.4 percentage points. Predictions of the nested logit model are similar but the cost sensitivity effect is larger in the conditional logit model.

Finally, we assess the impact of changes in tuition fees on enrollment. We find that a uniform 1000 euro tuition fee increase decreases participation by 3 percentage points for disadvantaged students and by 1.9 percentage points for other students. Since disadvantaged students are affected more, we also assess the impact of discriminatory tuition fee increases, where only advantaged students pay the extra 1000 euro, and disadvantaged students receive a subsidy in such a way that total government expenditures do not increase. We find that extending subsidies to all disadvantaged students, instead of only subsidizing low income students, decreases the gap in enrollment of disadvantaged students without decreasing total participation and without increasing the costs for the government.

Our findings have several implications for public policy. First, the low effects of tuition fee increases on enrollment (at least in a country where current fees only cover $3 \%$ of total costs) suggest that there is room to raise tuition fees. This is especially so if they are combined with additional subsidies to students from disadvantaged groups (broadly defined, i.e. not just low-income groups). Such policies can help to finance higher education without increasing the enrollment gap. Second, non-financial policies turn out to be quantitatively much more important to reduce the enrollment gap between advantaged and disadvantaged students. To raise enrollment of disadvantaged policies in higher education, governments should focus on reducing the gap in high school and ensure that more pupils from disadvantaged groups 
acquire sufficient academic skills to enroll in higher education.

\section{References}

Abraham, K. and Clark, M. (2006), Financial aid and students' college decisions: evidence from the district of Columbia tuition assistance grant program, The Journal of Human Resources $41(3), 578-610$

Acemoglu, D. and Pischke, J.-S. (2001), Changes in the wage structure, family income and children's education, European Economic Review 45, 890-904

Asplund, R., Ben Abdekkarim, O. and Skalli, A. (2008), An equity perspective on access to, enrolment in and finance of tertiary education, Education Economics 16(3), 261-274

Bailey, J. and Dynarski, S. (2011), Gains and gaps: changing inequality in U.S. college entry and completion, NBER working paper 17633

Baert, S. and Cockx, B. (2013), Pure ethnic gaps in educational attainment and school to work transitions: When do they arise?, Economics of Education Review 36, 276-294

Brownstone, D. and Train, K. (1999), Forecasting new product penetration with flexible substitution patterns, Journal of Econometrics 89, 109-129

Cameron, S. and Heckman, J. (2001), The dynamics of educational attainment for black, Hispanic, and white males, Journal of Political Economy 109(3), 455-499

Cantillon, E. and Declercq, K. (2012), University admission in practices - Belgium, matching in practice.eu, accessed $[11 / 02 / 2014]$

Cantillon, B., Verbist, G. and Segal, I. (2006), Student in de 21ste eeuw. Studie-financiering voor het hoger onderwijs in Vlaanderen, Over werk Tijdschrift van het Steunpunt WAV 1-2, $91-97$

Carneiro, P. and Heckman, J. (2002), The evidence of credit constraints in post-secondary schooling, The Economic Journal 112, 705-734

Cornwell, C., Mustard, B. and Sridhar, D. (2006), The enrollment effects of merit-based financial aid: evidence from Georgia's HOPE program, Journal of Labor Economics 24(4), 761-786 
Dahl, G. and Lochner, L. (2012), The impact of family income of child achievement: evidence from the earned income tax credit, American Economic Review 102(5), 1927-1957

Dassen, A. and Luijten-Lub, A. (2007), Higher education in Flanders, country report, Center for Higher Education and Policy Studies (CHEPS), International higher education monitor, Universiteit Twente

Declercq, K. and Verboven, F. (2014), Enrollment and degree completion in higher education without admission standards, CEPR discussion paper DP10037

Deming, D. and Dynarski, S. (2009), Into college, out of poverty? Policies to increase the postsecondary attainment of the poor, NBER working paper 15387

De Ro, J. (2008), Education in Flanders. A broad view on the Flemish education landscape, Agentschap voor Onderwijscommunicatie

Dynarski, S. (2002), The behavioral and distributional implications of aid for college, American Economic Review 92, 279-285

Dynarski, S. (2003), Does aid matter? Measuring the effect of student aid on college attendance and completion, American Economic Review 93, 279-288

Frenette, M. (2006), Too far to go on? Distance to school and university participation, Education Economics 14(1), 31-58

Galindo-Rueda, F., Marcenaro-Gutierez, O. and Vignoles, A. (2004), The widening socioeconomic gap in UK higher education, National Institute Economic Review 190: 75-88

Goodman, J. (2008), Who merits financial aid?: Massachusetts' Adams scholarship, Journal of Public Economics 92, 2121-2131

Jobdienst KU Leuven (2014), KU Leuven lonen voor jobstudenten, http://www.kuleuven.be/studentenvoorzieningen/jobdienst/kuleuvenjobstudent/kul_lonen, accessed $[01 / 07 / 2014]$

Kelchtermans, S. and Verboven, F. (2010), Participation and study decisions in a public system in higher education, Journal of Applied Econometrics 25, 355-39

Lundborg, P., Nilsson, A. and Rooth, D. (2014), Parental education and offspring outcomes: evidence from the Swedish compulsory school reform, American Economic Journal: Applied Economics 6(1), 253-278 
McFadden, D. (1978), Modelling the choice of residential location, In Spatial Interaction Theory and Planning Models, North-Holland: New York, 198-272

Ministerie van Onderwijs en Vorming (2014), School en studietoelagen, www.ond.vlaanderen.be/studietoelagen, accessed [12/02/2014]

Nielsen, H., Sorensen, T. and Taber, C. (2010), Estimating the effect of student aid on college enrollment: Evidence from a government grant policy reform, American Economic Journal: Economic Policy 2, 185-215

POD Maatschappelijke Integratie (2014), Wegwijs voor studenten, www.miis.be/sites/default/files/doc/wegwijs_voor_studenten.pdf, accesseds [11/08/2014]

Sociale dienst Universiteit Gent (2014), Raming van de totale kostprijs 2014-2015, http://www.ugent.be/student/nl/studeren/administratie/socialedienst/studeren/totaal.pdf, accessed [07/08/2014]

Steiner, V. and Wrohlich, K. (2012), Financial student aid and enrollment in higher education: New evidence from Germany, Scandinavian Journal of Economics 114(1), 124-147

Stinebrickner, R. and Stinebrickner T. (2003), Understanding the educational outcomes of students from low-income families: Evidence from a liberal arts college with a full tuition subsidy program, The Journal of Human Resources 38(3), 591-617

Train, K. (2009), Discrete choice models with simulation, Second edition, Cambridge University Press 


\section{Appendix}

Table A1: Conditional logit model

\begin{tabular}{|c|c|c|c|c|c|c|}
\hline \multirow[b]{3}{*}{ Variables } & \multicolumn{2}{|c|}{ no study option } & \multicolumn{4}{|c|}{ study options } \\
\hline & \multirow[b]{2}{*}{ Coef. } & \multirow[b]{2}{*}{ St. error } & \multicolumn{2}{|c|}{ university $^{a}$} & \multicolumn{2}{|c|}{ academic college $^{a}$} \\
\hline & & & Coef. & St. error & Coef. & St. error \\
\hline constant $\left(\alpha_{j}\right)$ & $0.678^{* * *}$ & $(0.0499)$ & $-1.366^{* * *}$ & $(0.0456)$ & $-2.492^{* * *}$ & $(0.125)$ \\
\hline \multicolumn{7}{|c|}{ Gender and high school background $\left(\beta_{j}\right)$} \\
\hline male & $0.308^{* * *}$ & $(0.0316)$ & $0.122^{* * *}$ & $(0.0309)$ & $0.652^{* * *}$ & $(0.0378)$ \\
\hline study delay & $0.675^{* * *}$ & $(0.0294)$ & $-0.294^{* * *}$ & $(0.0416)$ & $-0.171^{* * *}$ & $(0.0445)$ \\
\hline \multicolumn{7}{|l|}{ general $\mathrm{HS}^{b}$} \\
\hline clas + math & $-2.272^{* * *}$ & $(0.121)$ & $5.519 * * *$ & $(0.0830)$ & $3.083^{* * *}$ & $(0.153)$ \\
\hline clas + lang & $-2.980 * * *$ & $(0.117)$ & $4.369^{* * *}$ & $(0.0710)$ & $2.598^{* * *}$ & $(0.146)$ \\
\hline sci + math & $-3.291^{* * *}$ & $(0.0878)$ & $4.382^{* * *}$ & $(0.0556)$ & $2.989^{* * *}$ & $(0.130)$ \\
\hline math + lang & $-3.686^{* * *}$ & $(0.112)$ & $3.233^{* * *}$ & $(0.0642)$ & $2.219^{* * *}$ & $(0.138)$ \\
\hline $\mathrm{eco}+$ math & $-4.055^{* * *}$ & $(0.169)$ & $3.675^{* * *}$ & $(0.0768)$ & $2.672^{* * *}$ & $(0.145)$ \\
\hline eco + lang & $-4.427 * * *$ & $(0.0784)$ & $2.161^{* * *}$ & $(0.0506)$ & $1.707^{* * *}$ & $(0.126)$ \\
\hline human & $-4.331^{* * *}$ & $(0.0791)$ & $2.098^{* * *}$ & $(0.0521)$ & $0.817^{* * *}$ & $(0.136)$ \\
\hline \multicolumn{7}{|l|}{ technical $\mathrm{HS}^{b}$} \\
\hline business & $-3.925^{* * *}$ & $(0.0563)$ & & & 0.171 & $(0.138)$ \\
\hline $\mathrm{sci}+$ tech & $-4.333^{* * *}$ & $(0.0855)$ & & & $1.638^{* * *}$ & $(0.129)$ \\
\hline social + tech & $-3.845^{* * *}$ & $(0.0640)$ & & & $-0.428^{* *}$ & $(0.169)$ \\
\hline technics & $-2.199 * * *$ & $(0.0465)$ & & & 0.225 & $(0.143)$ \\
\hline other tech & $-2.496^{* * *}$ & $(0.0421)$ & & & 0.0750 & $(0.142)$ \\
\hline artistic $\mathrm{HS}^{b}$ & $-3.265^{* * *}$ & $(0.0960)$ & & & $2.788^{* * *}$ & $(0.134)$ \\
\hline \multicolumn{7}{|c|}{ Socio-economic status $\left(\gamma_{j}\right)$} \\
\hline mother no SE degree ${ }^{c}$ & $0.144^{* * *}$ & $(0.0526)$ & $-0.452^{* * *}$ & $(0.0472)$ & $-0.377^{* * *}$ & $(0.0549)$ \\
\hline mother SE degree $^{c}$ & 0.0206 & $(0.0454)$ & $-0.395^{* * *}$ & $(0.0328)$ & $-0.270^{* * *}$ & $(0.0386)$ \\
\hline no dutch at home & $0.388^{* * *}$ & $(0.0730)$ & $0.177^{* *}$ & $(0.0690)$ & $0.190^{* *}$ & $(0.0835)$ \\
\hline low income & $1.818^{* * *}$ & $(0.0412)$ & $-0.170 * * *$ & $(0.0401)$ & $0.0791^{*}$ & $(0.0461)$ \\
\hline
\end{tabular}

Note: standard errors in parentheses; ${ }^{* * *} \mathrm{p}<0.01,{ }^{*} * \mathrm{p}<0.05,{ }^{*} \mathrm{p}<0.1$

${ }^{a}$ Base category $=$ professional college program

${ }^{b}$ Base category $=$ technical + artistic + vocational secondary education for university, vocational secondary education for college

${ }^{c}$ Base category $=$ mother has a degree in higher education 
Table A1 (continued): Conditional logit model

\begin{tabular}{lcc}
\hline Variables & Coef. & St. error \\
\hline Cost sensitivity $(\delta)$ & $-0.845^{* * *}$ & $(0.00576)$ \\
\multicolumn{2}{l}{. } & \\
Cost sensitivity and socio-economic status $(\phi)$ & \\
mother no SE degree ${ }^{c}$ & $-0.134^{* * *}$ & $(0.0112)$ \\
mother SE degree & $-0.0922^{* * *}$ & $(0.00849)$ \\
no dutch at home & $-0.152^{* * *}$ & $(0.0193)$ \\
low income & $-0.165^{* * *}$ & $(0.0125)$ \\
Log likelihood & & $-125,519.7$ \\
\hline
\end{tabular}

Note: standard errors in parentheses; *** $\mathrm{p}<0.01,{ }^{* *} \mathrm{p}<0.05, * \mathrm{p}<0.1$

${ }^{c}$ Base category $=$ mother has a degree in higher education 
Table A2: Nested logit model

\begin{tabular}{|c|c|c|c|c|c|c|}
\hline \multirow[b]{3}{*}{ Variables } & \multicolumn{2}{|c|}{ no study option } & \multicolumn{4}{|c|}{ study options } \\
\hline & \multirow[b]{2}{*}{ Coef. } & \multirow[b]{2}{*}{ St. error } & \multicolumn{2}{|c|}{ university $^{a}$} & \multicolumn{2}{|c|}{ academic college $^{a}$} \\
\hline & & & Coef. & St. error & Coef. & St. error \\
\hline constant $\left(\alpha_{j}\right)$ & $0.954^{* * *}$ & $(0.044)$ & $-0.348^{* * *}$ & $(0.031)$ & $-0.634^{* * *}$ & $(0.062)$ \\
\hline \multicolumn{7}{|c|}{ Gender and high school background $\left(\beta_{j}\right)$} \\
\hline male & $0.249^{* * *}$ & $(0.030)$ & $0.039^{* * *}$ & $(0.009)$ & $0.172^{* * *}$ & $(0.017)$ \\
\hline study delay & $0.590^{* * *}$ & $(0.028)$ & $-0.086^{* * *}$ & $(0.013)$ & $-0.047 * * *$ & $(0.012)$ \\
\hline \multicolumn{7}{|l|}{ general $\mathrm{HS}^{b}$} \\
\hline clas + math & $-3.994^{* * *}$ & $(0.113)$ & $1.415^{* * *}$ & $(0.117)$ & $0.791^{* * *}$ & $(0.076)$ \\
\hline clas + lang & $-3.990 * * *$ & $(0.110)$ & $1.122^{* * *}$ & $(0.093)$ & $0.669^{* * *}$ & $(0.067)$ \\
\hline sci + math & $-4.300 * * *$ & $(0.086)$ & $1.123^{* * *}$ & $(0.092)$ & $0.766^{* * *}$ & $(0.071)$ \\
\hline math + lang & $-4.158 * * *$ & $(0.107)$ & $0.828 * * *$ & $(0.069)$ & $0.569 * * *$ & $(0.059)$ \\
\hline $\mathrm{eco}+$ math & $-4.695^{* * *}$ & $(0.162)$ & $0.943^{* * *}$ & $(0.079)$ & $0.686^{* * *}$ & $(0.068)$ \\
\hline eco + lang & $-4.483^{* * *}$ & $(0.075)$ & $0.554^{* * *}$ & $(0.047)$ & $0.438^{* * *}$ & $(0.049)$ \\
\hline human & $-4.312^{* * *}$ & $(0.075)$ & $0.542^{* * *}$ & $(0.046)$ & $0.214^{* * *}$ & $(0.039)$ \\
\hline \multicolumn{7}{|l|}{ technical $\mathrm{HS}^{b}$} \\
\hline business & $-3.669 * * *$ & $(0.053)$ & & & 0.044 & $(0.035)$ \\
\hline sci + tech & $-4.137 * * *$ & $(0.081)$ & & & $0.419 * * *$ & $(0.048)$ \\
\hline social + tech & $-3.541 * * *$ & $(0.061)$ & & & $-0.105^{* *}$ & $(0.044)$ \\
\hline technics & $-1.998^{* * *}$ & $(0.044)$ & & & 0.058 & $(0.037)$ \\
\hline other tech & $-2.349 * * *$ & $(0.040)$ & & & 0.015 & $(0.036)$ \\
\hline artistic $\mathrm{HS}^{b}$ & $-3.434^{* * *}$ & $(0.089)$ & & & $0.716^{* * *}$ & $(0.068)$ \\
\hline \multicolumn{7}{|c|}{ Socio-economic status $\left(\gamma_{j}\right)$} \\
\hline mother no SE degree ${ }^{c}$ & $0.435^{* * *}$ & $(0.041)$ & $-0.138^{* * *}$ & $(0.016)$ & $-0.110 * * *$ & $(0.016)$ \\
\hline mother SE degree $^{c}$ & $0.293^{* * *}$ & $(0.036)$ & $-0.109^{* * *}$ & $(0.012)$ & $-0.075^{* * *}$ & $(0.012)$ \\
\hline no dutch at home & $0.257^{* * *}$ & $(0.061)$ & $0.138^{* * *}$ & $(0.020)$ & $0.097^{* * *}$ & $(0.023)$ \\
\hline low income & $0.283^{* * *}$ & $(0.052)$ & $-0.059 * * *$ & $(0.011)$ & 0.014 & $(0.012)$ \\
\hline
\end{tabular}

Note: standard errors in parentheses; *** $\mathrm{p}<0.01,{ }^{* *} \mathrm{p}<0.05, * \mathrm{p}<0.1$

${ }^{a}$ Base category $=$ professional college program

${ }^{b}$ Base category $=$ technical + artistic + vocational secondary education for university, vocational secondary education for college

${ }^{c}$ Base category $=$ mother has a degree in higher education 
Table A2 (continued): Nested logit model

\begin{tabular}{lcc}
\hline Variables & Coef. & St. error \\
\hline Cost sensitivity $(\delta)$ & $-0.219^{* * *}$ & $(0.018)$ \\
\multicolumn{2}{l}{ Cost sensitivity and socio-economic status $(\phi)$} & \\
$\quad$ mother no SE degree ${ }^{c}$ & $-0.046^{* * *}$ & $(0.005)$ \\
mother SE degree ${ }^{c}$ & $-0.033^{* * *}$ & $(0.004)$ \\
no dutch at home & $-0.023^{* * *}$ & $(0.006)$ \\
low income & $-0.080^{* * *}$ & $(0.007)$ \\
Nesting parameter $(\lambda)$ & & $(0.021)$ \\
Log likelihood & $0.254^{* * *}$ & \\
\hline
\end{tabular}

Note: standard errors in parentheses; ${ }^{* * *} \mathrm{p}<0.01,{ }^{* *} \mathrm{p}<0.05,{ }^{*} \mathrm{p}<0.1$

${ }^{c}$ Base category $=$ mother has a degree in higher education

Table A3: Relaxing the impact of socio-economic background

\begin{tabular}{ccccc}
\hline & univ & acad coll & prof coll & total \\
\hline Observed choices & 23.8 & 8.3 & 37.8 & 69.8
\end{tabular}

Conditional logit model

$\begin{array}{lllll}\text { Status quo } & 23.8 & 8.3 & 37.8 & 69.8\end{array}$

Relaxing the impact of socio-economic background

$\begin{array}{lcccc}\text { Cost effect } & +0.1 & +0.1 & +1.2 & +1.4 \\ \text { Preference effect } & +1.1 & +0.3 & +3.3 & +4.7 \\ \text { Ability effect } & +4.7 & +1.1 & +0.9 & +6.6 \\ \text { All effects } & +6.4 & +1.4 & +3.1 & +10.9\end{array}$

\section{Nested logit model}

$\begin{array}{lllll}\text { Status quo } & 23.8 & 8.3 & 37.8 & 69.8\end{array}$

Relaxing the impact of socio-economic background

\begin{tabular}{lcccc} 
Cost effect & +0.0 & +0.1 & +0.5 & +0.5 \\
Preference effect & +0.8 & +0.2 & +0.5 & +1.5 \\
Ability effect & +4.7 & +1.1 & +0.9 & +6.5 \\
All effects & +6.2 & +1.2 & +1.2 & +8.6 \\
\hline
\end{tabular}

Note: Observed and predicted outcomes are expressed as percentages of 2008 high school graduates.

The effects of the counterfactuals are expressed as percentage point changes relative to the predicted choice probabilities 
Table A4: The impact of alternative tuition fee policies

\begin{tabular}{|c|c|c|c|c|}
\hline & univ & acad coll & prof coll & total \\
\hline \multicolumn{5}{|l|}{ Observed choices } \\
\hline all students & 23.8 & 8.3 & 37.8 & 69.8 \\
\hline advantaged students & 29.5 & 9.5 & 38.2 & 77.2 \\
\hline disadvantaged students & 14.3 & 6.2 & 37.1 & 57.6 \\
\hline \multicolumn{5}{|l|}{ Nested logit model } \\
\hline \multicolumn{5}{|l|}{ Status quo } \\
\hline all students & 23.8 & 8.3 & 37.8 & 69.8 \\
\hline advantaged students & 29.3 & 9.5 & 37.9 & 75.4 \\
\hline disadvantaged students & 14.7 & 6.2 & 37.6 & 58.5 \\
\hline \multicolumn{5}{|l|}{ Uniform tuition fee increase $^{a}$} \\
\hline all students & -0.3 & -0.2 & -2.2 & -2.8 \\
\hline advantaged students & -0.3 & -0.2 & -1.7 & -2.3 \\
\hline disadvantaged students & -0.4 & -0.3 & -3.0 & -3.6 \\
\hline \multicolumn{5}{|c|}{ Cost neutral tuition policy ${ }^{b}$ with subsidy for low income students } \\
\hline all students & -0.2 & -0.1 & -0.5 & -0.7 \\
\hline advantaged students & -0.3 & -0.2 & -1.5 & -2.0 \\
\hline disadvantaged students & +0.1 & +0.1 & +2.5 & +2.7 \\
\hline \multicolumn{5}{|c|}{ Redistributive tuition fee policy $^{b}$} \\
\hline all students & -0.1 & -0.0 & +0.1 & -0.1 \\
\hline advantaged students & -0.3 & -0.2 & -1.7 & -2.3 \\
\hline disadvantaged students & +0.3 & +0.2 & +3.0 & +3.6 \\
\hline
\end{tabular}

Note: Observed and predicted outcomes are expressed as percentages of 2008 high school graduates.

Outcomes of the counterfactual policies are expressed as percentage point changes relative to the status quo.

${ }^{a}$ Tuition fee increase of 1000 euro for all students in all options in higher education.

${ }^{b}$ Subsidy of 1400 euro for low income students financed by a 1000 euro cost increase for other students

${ }^{c}$ Subsidy of 1000 euro for disadvantaged students financed by a 1000 euro cost increase for advantaged students. 
Table A5: The impact of alternative tuition fee policies

\begin{tabular}{|c|c|c|c|c|}
\hline & univ & acad coll & prof coll & total \\
\hline \multicolumn{5}{|l|}{ Observed choices } \\
\hline all students & 23.8 & 8.3 & 37.8 & 69.8 \\
\hline advantaged students & 29.5 & 9.5 & 38.2 & 77.2 \\
\hline disadvantaged students & 14.3 & 6.2 & 37.1 & 57.6 \\
\hline \multicolumn{5}{|l|}{ Conditional logit model } \\
\hline \multicolumn{5}{|l|}{ Status quo } \\
\hline all students & 23.8 & 8.3 & 37.8 & 69.8 \\
\hline advantaged students & 29.4 & 9.6 & 38.0 & 77.0 \\
\hline disadvantaged students & 14.6 & 6.2 & 37.5 & 58.3 \\
\hline \multicolumn{5}{|l|}{ Uniform tuition fee increase $^{a}$} \\
\hline all students & -1.4 & -0.9 & -7.4 & -9.7 \\
\hline advantaged students & -1.5 & -0.8 & -6.2 & -8.5 \\
\hline disadvantaged students & -1.4 & -1.0 & -9.4 & -11.8 \\
\hline \multicolumn{5}{|c|}{ Cost neutral tuition policy ${ }^{b}$ with subsidy for low income students } \\
\hline all students & -1.1 & -0.6 & -4.0 & -5.6 \\
\hline advantaged students & -1.4 & -0.8 & -6.0 & -8.2 \\
\hline disadvantaged students & -0.4 & -0.2 & -0.7 & -1.3 \\
\hline \multicolumn{5}{|c|}{ Cost neutral tuition policy $^{c}$ with subsidy for disadvantaged students } \\
\hline all students & -0.7 & -0.4 & -2.0 & -3.1 \\
\hline advantaged students & -1.5 & -0.8 & -6.2 & -8.5 \\
\hline disadvantaged students & +0.5 & +0.4 & +4.9 & +5.8 \\
\hline
\end{tabular}

Note: Observed and predicted outcomes are expressed as percentages of 2008 high school graduates.

Outcomes of the counterfactual policies are expressed as percentage point changes relative to the status quo.

${ }^{a}$ Tuition fee increase of 1000 euro for all students in all options in higher education.

${ }^{b}$ Subsidy of 600 euro for low income students financed by a 1000 euro cost increase for other students.

${ }^{c}$ Subsidy of 500 euro for disadvantaged students financed by a 1000 euro cost increase for advantaged students. 